\title{
Nutritionally induced congenital defects
}

By Mary J. Seller, The Prince Philip Research Laboratories, The United Medical and Dental Schools of Guy's and St Thomas' Hospitals, Guy's Campus, London $S E_{\text {I }} 9 R T$

Once upon a time it was thought that, since the mammalian embryo develops deep inside its mother, it is protected from all adverse environmental influences. This belief was seriously shaken in the r 940 s by the teratological experiments of Warkany and his colleagues in rodents (Warkany \& Schraffenberger, I943, 1944; Wilson \& Warkany, 1948, 1950).

Amongst the many agents they investigated were maternal dietary deficiencies. They demonstrated that both hypovitaminosis $\mathrm{A}$ and lack of riboflavin during early pregnancy caused congenital defects in the offspring, the former producing abnormalities of the eye and the urogenital tract (Warkany \& Schraffenberger, 1944; Wilson \& Warkany, 1948), the latter, skeletal defects and cleft palate (Warkany \& Schraffenberger, 1943). The science of teratology then expanded and the manipulation of nutritional factors was central to its work and to the establishment of various teratogenic principles. It became evident that not only deficiencies, but also excesses, of dietary substances, cause congenital defects. As the years have passed, clinical evidence has been gathered to show that in humans too, maternal dietary deficiencies and excesses are associated with congenital defects in the offspring.

It is perhaps surprising that this fact was not appreciated earlier, for the mammalian embryo develops as a result of the elaboration of the genetic information it bears, powered by nutrients supplied by the environment. The embryo itself contains none of the factors necessary for growth and differentiation, other than the basic instructions, so these factors must be derived from the mother.

\section{Phases of embryonic development}

There are three distinct phases to prenatal development. Initially, in the pre-implantation stage, the embryo grows very little in overall size. Cleavage occurs producing more and more, smaller and smaller cells. After implantation, the embryonic period begins and, as the basic body structure is laid down, formation and differentiation of the major organs occurs, and the embryo begins to enlarge. Finally, once organogenesis has taken place, there is a phase of intense growth, which is often prolonged.

Nutrition does not usually affect the pre-implantation phase, but alterations of nutritional factors during the other two can have marked effects. However, it is only when they occur during the embryonic period that they may actually alter the 
process of development, distorting organogenesis to produce overt developmental malformations such as neural tube defects (NTD), cleft palate and congenital heart defects. When nutritional changes occur during the final growth phase, the effects are more subtle, and actual developmental defects are not produced. Instead, disruptions such as microcephaly occur, resulting from reduced proliferation of cells in a normally formed organ.

\section{Embryonic nutrition}

The way nutrients from the mother reach the embryo differs according to the developmental stage. This has been studied particularly well in the rat. In the pre-implantation period the embryo lies free in the fluid lining the fallopian tubes and the uterus and it acquires nutrients by diffusion. In the early post-implantation period, which includes the major part of organogenesis, the placenta is not yet established and the embryonic yolk sac endocytizes macromolecular components of the maternal serum exudate which surrounds the embryo as it invades the endometrium. This is called histiotrophic nutrition, and it continues until the chorio-allantoic placenta has been established and a functioning heart and blood circulation has developed. For the remainder of gestation, exchange of nutrients occurs across the placental membrane which separates the maternal and fetal blood systems. Many substances, including some vitamins, do not simply diffuse across the placental barrier but are actively transported. Thus, a deficiency of nutrients in the embryo need not result simply from a deficiency in the mother but could be caused, initially, by a defect in the process of histiotrophic nutrition or, later, by a faulty placental transfer system.

\section{Nutritional factors and congenital defects}

The literature on nutritional factors causing congenital defects is so extensive now that it is not possible to give a comprehensive review in a short paper. In brief, overall, it seems that general malnutrition during pregnancy, although deleterious, is less likely to produce specific congenital malformations than deficiencies of individual dietary substances. Often, as previously mentioned, excesses of the same substances also produce malformations. Major abnormalities have been observed to occur if the diet is poor in, for example, certain amino acids such as methionine, cysteine, tryptophan or leucine, and if there is an excess of glutamate or aspartate. In man, excess phenylalanine has long been known to be deleterious from observations on the offspring of women with phenylketonuria. Of the minerals and trace elements, a lack of magnesium, manganese or zinc causes major malformations, as do deficiencies or excesses of virtually all the vitamins. Amino acids, minerals and vitamins are involved in basic cellular metabolic processes such as protein and DNA synthesis, and minerals and vitamins often act as vital co-factors for enzymes. Although actual mechanisms for the production of malformations are not known, it can be imagined that any dysfunction in such fundamental processes of cells will have a far-reaching effect on embryogenesis 
which proceeds through a programmed sequence of rapid cell division and cell differentiation, so that dysmorphogenesis is a likely result.

\section{Vitamin A teratogenesis}

Vitamin $A$ is a well-worked example of an individual nutrient which affects development. As long ago as 1933, Hale observed that a vitamin-A-deficient sow delivered piglets without eyeballs (Hale, 1933). Hypovitaminosis A was studied in more detail in the rat where, in addition to eye defects, it was also found to be associated with anomalies of the cardiovascular system (Wilson \& Warkany, 1950) and of the urogenital tract (Wilson \& Warkany, 1948). Excess of vitamin $A$ also causes multisystem defects but, experimentally, it has been found that the actual malformation depends on the stage in pregnancy in which exposure to the vitamin occurs. It is one of the principles of teratogenesis that each organ or system has only a brief time in its development when it is susceptible to gross alteration. This is known as the 'critical period' and it pertains usually immediately before, and during, the formation of the organ. At all other times, even if the extraneous influence is present there is little or no effect on that organ. So, in the rat, hypervitaminosis $A$ at any time from day 5 to day 8 of pregnancy produces NTD but not limb malformations. The latter are produced on days 10-12 at which time the central nervous system is unaffected. Defects of the eye, palate and face occur when excess vitamin $A$ is given on days 7-10 (Morriss, 1973). Under normal circumstances in man, if nutritional derangement is a factor, then it is generally present for a prolonged period and even throughout pregnancy, but critical periods have been reliably demonstrated for the drug thalidomide, in women who took only one or a few tablets, and for the Rubella virus.

Recently, there have been reports of malformations in babies closely resembling those observed with hypervitaminosis $A$ in rodents: face defects (microtia and anotia, micrognathia and cleft palate), eye and cardiac defects and malformations of the central nervous system. These have been linked with the mother having taken the drug 'Accutane' in early pregnancy (Rosa, 1983; Braun et al. 1984; Lammer et al. 1985). This agent is used for treating severe acne, and is isotretinoin, a vitamin $A$ analogue. Very large doses are administered (40 mg once or twice daily), which are of the same order as those used in the teratogenic experiments in rodents.

The pathogenesis of the lesions produced by excess vitamin $\mathbf{A}$ has been studied in rodent embryos, although the actual mechanisms are not firmly established. Hypervitaminosis A reduces the rate of cell proliferation in the neurulating embryo (Kochhar, 1968) and, more specifically, lengthens the cell cycle in the neuroepithelium (Langman \& Welch, 1966). This possibly leads to asynchrony between the morphogenetic processes of the three primary germ layers which results in developmental abnormalities, particularly those affecting the central nervous system (Morriss, 1973; Hurley, 1977). Defects relating to cranio-facial development and the heart may possibly arise in a different way (Lammer et al. 1985 ) through impairment of cell migration leading to a deficiency of mesodermal 
cells. Excess vitamin $A$ interferes with the migration of both primary mesenchyme (Morriss, 1975) and neural crest cells (Wiley et al. 1983). This may be related to its effect on the cell membrane which includes an alteration in the metabolism of sulphated mucopolysaccharides on the cell surface (Kochhar, 1968) and changes in cell adhesiveness and cell-extracellular matrix interaction (Thorogood et al. I982).

\section{The curly-tail mouse}

Excess vitamin $A$, as retinoic acid, has an interesting effect on the curly-tail mouse, an animal model of human NTD. About $60 \%$ of these mice have either spina bifida cystica or a curly-tail, both caused by delayed closure of the posterior neuropore and occasionally exencephaly (Grüneberg, I954; Copp et al. 1982), due to the action of a mutant gene which is only partially penetrant (Grüneberg, 1954; Embury et al. 1979). If large doses of vitamin A are administered to the mother on day 8 of pregnancy, the incidence of tail and neural tube abnormalities in the embryos is increased. Certain doses produce $100 \%$ affected individuals. Overall, however, the dose levels are less than those required to produce NTD in mice which are not genetically predisposed. Paradoxically, if the excess vitamin $A$ is given on the next day of gestation, day 9 , then the incidence of spine and tail abnormalities is markedly reduced to about $30 \%$, which is way below the number occurring spontaneously (Seller et al. 1979). Thus, in this model of individuals genetically susceptible to a particular malformation (NTD), according to the precise time in embryogenesis when a particular nutritional factor is administered, malformations of the neural tube are either produced or prevented. A similar gene-environment interaction has recently been demonstrated in another mouse mutant affecting the neural tube - splotch (Kapron-Bras \& Trasler, 1985).

Further experiments in the curly-tail mouse have shown that other agents introduced into the pregnant female on day 9 are equally good, or even better, at reducing the number of NTD in the offspring. These include hydroxyurea (Seller \& Perkins, 1983), 5-fluorouracil (Seller, 1983) and mitomycin C (Seller \& Perkins, 1986). These are all inhibitors of DNA synthesis and although one would hesitate to administer such cytotoxic agents to pregnant humans, such experiments do show that the occurrence of NTD can be manipulated to advantage by the alteration of environmental factors, and so is a feasible approach to primary, that is true, prevention. Such a method has long been sought by clinicians for human NTD and has only recently met with probable success.

\section{Cause of human NTD}

Human NTD, anencephaly, spina bifida and related abnormalities, are considered to be multifactorial in origin, with both a genetic predisposition and environmental factors contributing additively to the cause (Carter, 1974). Both the genetic and the environmental components must be present for the defect to be triggered. 
For a long time, investigations aiming to identify the actual environmental factor, or factors, implicated in the cause focussed on dietary excesses, or possible teratogenic substances in food ingested. Epidemiological studies found associations between NTD in the offspring and excessive tea drinking (Fedrick, 1974) and the consumption of ice cream, white bread loaves, canned meats, canned peas and corned beef (Knox, 1972) by the mother during pregnancy. Knox suggested that the nitrites and nitrates used for preserving canned foods may be teratogens. Previously, Penrose (1957) had observed that areas in the UK where the prevalence of NTD was the highest were also those areas where the drinking water was soft rather than hard, and suggested that the presence or absence of certain trace elements may be an important factor in causation. However, none of these associations has been established as a proven cause of NTD. A theory which perhaps provoked the most attention was that of Renwick (1972) which suggested that the causal agent was an unidentified substance occurring in blighted potatoes, so that if women avoided ingesting such potatoes they would not have NTD offspring. This was found not to be the case by Nevin \& Merrett (1975). A group of their patients, each of whom had had at least one affected child, not only did not eat potatoes themselves before and during the next pregnancy, but neither did their families. These women therefore totally avoided even contact with potatoes, yet they still had further offspring with NTD.

Other strands of evidence suggest that a dietary deficiency could be important. Although, as previously stated, malnutrition is not generally associated with the production of specific abnormalities, there was a significant excess of NTD in the offspring of women exposed in the first trimester of pregnancy to the Dutch famine of 1944-45 (Stein \& Susser, 1976). In the UK it has long been known that NTD show a marked social-class gradient, being more common in lower socio-economic classes. Though many factors could operate here, poor nutrition is one. In the UK too, there is an increasing prevalence from the South-east to the North-west. The areas of highest prevalence: Northern Ireland, South Wales and Western Scotland, are those where Celtic genes predominate and, incidentally, where soft water occurs, but are also the areas of greatest poverty and deprivation.

Two studies in South Wales have noted an association between poor diet and the prevalence of NTD (Richards, 1969; Laurence et al. 1980). The studies were retrospective and subject to criticism because women who had given birth to NTD infants were required to recall their diet in early pregnancy. Laurence et al. (1980) found that $53 \%$ of these women had had a poor diet while only $10 \%$ were classified as 'good'. They also demonstrated the beneficial effects of dietary counselling. Women who were assessed as being on a poor diet were counselled as to the desirability of improving their diet before the next pregnancy, by eliminating excessive amounts of refined carbohydrates and fats and including plenty of fresh meat, fish, green vegetables and fruit, and by having regular meal patterns. Of those who had another pregnancy, only $18 \%$ remained on a poor diet, and all the five recurrences of NTD occurred in that group. 
A study aimed more specifically at trying to identify individual dietary factors examined the levels of certain blood vitamins in the first trimester of pregnancy (Smithells et al. 1976). There were two major findings: first, that there was a social-class gradient with respect to the components studied; erythrocyte folate, leucocyte vitamin $C$, riboflavin and serum vitamin $A$ were all significantly higher in social classes I and II than in the lower classes. Second, the women who were carrying fetuses with NTD had significantly lower erythrocyte folate and leucocyte vitamin $\mathrm{C}$ than women with normal fetuses, even when corrected for social class. Subsequently, Schorah et al. (1980) found that maternal vitamin $B_{12}$ levels were low when the fetus was anencephalic.

\section{Primary prevention of NTD}

These findings led Smithells to the hypothesis that minor nutritional deficiencies could be significant in the cause of NTD (Smithells et al. 1976) and he organized an intervention study to test the idea. It consisted of giving vitamin supplements (Pregnavite Forte F; Bencard) to women who had already had one or more children with NTD, while they were trying to get pregnant again and for the first 8 weeks after conception. The nutrient supplements therefore covered the time of neural tube formation in the embryo, which occurs from about the igth to the 26th day of life. Pregnavite Forte F is a multivitamin and mineral tablet with folic acid and iron, the individual components being in quantities close to the US recommended daily allowance (RDA). The study was undertaken jointly in several centres within the UK, including both high- and low-incidence areas. The recurrences of NTD in the supplemented women were compared with those of women from the same areas who were at a similar risk and who conceived at the same time. These women did not receive placebos because ethical permission was not granted for this.

The results have been published in several stages within the continuing study which began in 1976 . In the first cohort of 178 babies whose mothers had been fully supplemented, there was one recurrence of NTD (0.56\%), which was markedly lower than the $5 \%$ of the untreated women (Smithells et al. 1980). The second cohort of 234 babies had two recurrences $(0.85 \%)$, as against $5.1 \%$ in the untreated group (Smithells et al. 1983 ). Subsequently, other centres in the UK have joined in the careful documenting of supplemented women and, as the numbers increase, the trend for reduction of recurrence of NTD with periconceptional vitamin supplementation continues. The latest available information, published in June 1985 , showed that of a total of 1080 babies, ten had NTD, a recurrence of $0.93 \%$ (Seller, 1985 ).

Thus, although it would seem that recurrences of NTD have been prevented, no one has yet undertaken an occurrence study in the general population, that is, preventing the first affected child in a family. The logistics are formidable, but there is no reason to believe it would not be successful.

The question must be asked as to whether any harm is being done by such therapy. The incidence of congenital abnormalities other than NTD amongst the 
1080 babies mentioned previously is $2.9 \%$ (Seller, 1985 ), which is no greater than expected. Possibly vitamin $A$ is the most worrying component of Pregnavite Forte $F$ on this score, but the daily intake is only $1 \cdot 2 \mathrm{mg}$ ( $4000 \mathrm{IU}$ ) which compares favourably with the US RDA of $\mathrm{I} \cdot 5 \mathrm{mg}$ ( $5000 \mathrm{IU})$. Both these are in marked contrast to the $40 \mathrm{mg}$ ( $130000 \mathrm{IU}$ ) in 'Accutane' which seems to be teratogenic.

In view of the fact that Tolarova (1982) presented preliminary evidence that similar multivitamin therapy has prevented recurrences of cleft lip in Czechoslovakia, it should be noted that a case of cleft lip and of cleft palate occurred amongst the other abnormalities in the supplemented group.

Further, it is considered by some that NTD are actually part of a larger and more general group of states of faulty midline closure (Czeizel, r981; Opitz \& Gilbert, I982), which includes cleft lip and cleft palate, omphalocoele and probably congenital heart defects. So it is also of interest to note the occurrence of omphalocoele and heart abnormalities in the babies of supplemented mothers. It is possible that these observations represent preliminary indications of specificity for NTD in the preventive effects of vitamin therapy.

Schorah et al. ( 1983 ) have examined the blood vitamin levels of women at intervals after the commencement of supplementation and found them raised, and so concluded that women who have had an NTD child do not seem to have any defect in vitamin absorption which cannot be overcome by supplementation. The first patient to have a recurrence of NTD, although fully supplemented, had similarly elevated levels (M. J. Seller, unpublished results), so the fact remains that despite successful supplementation, there are still some occurrences of NTD. However, this is not really surprising because NTD are heterogeneous and it would have been rather more surprising if there had been only one cause. Furthermore, it must be remembered the mother's blood may well be far removed both physiologically and in metabolic terms from the primary site of action, which is probably in the cells of the neural plate and underlying mesoderm of the embryo. There could be a defect of embryonic uptake from the maternal compartment or in embryonic transport. On a completely different tack, the effect of the nutrients might be far more indirect; for example, they may neutralize another dietary substance which is toxic (Renwick, 1982).

Pregnavite Forte $\mathrm{F}$ contains seven vitamins as well as $\mathrm{Fe}$, folic acid and various minerals. It is not known whether one of these alone is the active agent, or whether several act in concert. The favoured candidate for a single agent is folic acid because of earlier maternal blood studies, and also because of a very small trial with folic acid alone in 'at risk' women in South Wales, which did include a placebo group (Laurence et al. $198 \mathrm{I}$ ). There were fewer recurrences in the folate-treated group than in the controls, but the difference was not significant. However, it was later found that it was likely that the two women who had recurrences in the supplemented group had not taken their tablets, so the results may be more positive than is immediately indicated.

Finally, a more speculative issue is the more far-reaching question of apparent malnutrition figuring in a Western industrialized society. It has been suggested ( $\mathrm{St}$ 
George, 1983) that although overt malnutrition has been eradicated, it has been replaced by a more subtle form of deprivation produced by modern methods of food production and food processing. The demand now is for food products, rather than food, which are clean and attractive, and the scientific farming and food processing involved in their production lead to the loss of micronutrients (Bender, 1978). It would appear that Western society is not frankly malnourished now, but subtly so. If this is the case, then as far as NTD are concerned, in a population such as that of the UK, which is already genetically predisposed to NTD, this fact of frank or subtle malnutrition is immaterial, the net result is the same, the environmental factor which triggers the genetic predisposition is present, and NTD are produced.

\section{REFERENCES}

Bender, A. E. (1978). Food Processing and Nutrition. London: Academic Press.

Braun, J. T., Franciosi, R. A., Mastri, A. R., Drake, R. M. \& O'Neil, B. L. (1984). Lancet i, 506-507.

Carter, C. O. (1974). Developmental Medicine and Child Neurology 16, Suppl. 32, $3^{-1} 5$.

Copp, A. J., Seller, M. J. \& Polani, P. E. (1982). Fournal of Embryology and Experimental Morphology 69, $15 \mathrm{I}-167$.

Czeizel, A. (1981). American Fournal of Medical Genetics 10, 25-35.

Embury, S., Seller, M. J., Adinolf, M. \& Polani, P. E. (I979). Proceedings of the Royal Society, London series B 206, 85-94.

Fedrick, J. (1974). Proceedings of the Royal Society of Medicine 67, 356-360.

Grüneberg, H. (1954). Journal of Genetics 52, 52-67.

Hale, F. (1933). Fournal of Heredity 24, $105-106$.

Hurley, L. S. (1977). In Handbook of Teratology, vol. 1., General Principles and Etiology, pp. 26r-310 [J. G. Wilson and F. C. Fraser, editors]. New York and London: Plenum Press.

Kapron-Bras, C. M. \& Trasler, D. G. (1985). Teratology 32, 87-92.

Knox, E. C. (1972). British fournal of Preventive and Social Medicine 26, $219-223$.

Kochhar, D. M. (1968). Teratology 1, 299-310.

Lammer, E. J., Chen, D. T., Hoar, R. M., Agnish, N. D., Benke, P. J., Braun, J. T., Curry, C. J., Fernoff, P. M., Grix, A. W., Lott, I. T., Richard, J. M. \& Sun, S. C. (1985). Nevo England fournal of Medicine $313,837-84 \mathrm{I}$.

Langman, J. \& Welch, G. W. (I g66). Fournal of Comparative Neurology 128, I-16.

Laurence, K. M., James, N., Miller, M. H., Tennant, G. B. \& Campbell, H. (1980). British Medical fournal 281, $1542-1544$.

Laurence, K. M., James, N., Miller, M. H., Tennant, G. B. \& Campbell, H. (I98I). British Medical fournal 282, I 509-I 5 I I.

Morriss, G. M. (1973). Fournal of Embryology and Experimental Morphology 30, 219-242.

Morriss, G. M. (1975). In New Approaches to the Evaluation of Abnormal Embryonic Development, pp. 678-687 [D. Neubert and H. J. Merker, editors]. Stuttgart: Thieme-Edition Publishing Sciences Group Inc.

Nevin, N. C. \& Merrett, J. D. (1975). British Yournal of Preventive and Social Medicine 29, III-II5.

Opitz, J. M. \& Gilbert, E. F. (1982). American fournal of Medical Genetics 12, 443-455.

Penrose, L. S. (1957). Journal of Mental Deficiency Research 1, 4-1 5 .

Renwick, J. H. (1972). British fournal of Preventive and Social Medicine 26, 67-88.

Renwick, J. H. (r982). Lancet i, 748 .

Richards, I. D. G. (1969). British Journal of Preventive and Social Medicine 25, 59-64.

Rosa, F. W. ( 1983$)$. Lancet ii, $5{ }^{1} 3$.

St George, D. (1983). Nutrition and Health 2, 71-75.

Schorah, C. J., Smithells, R. W. \& Scott, J. (1980). Lancet i, 880. 
Schorah, C. J., Wild, J., Hartley, R., Sheppard, S. \& Smithells, R. W. (1983). British fournal of Nutrition 49, 203-21 2.

Seller, M. J. (1983). Fournal of Medical Genetics 20, $164^{-1} 68$.

Seller, M. J. ( 1985 ). Lancet i, $1392-1393$.

Seller, M. J., Embury, S., Polani, P. E. \& Adinolfi, M. (1979). Proceedings of the Royal Society, London series B 206, 95-107.

Seller, M. J. \& Perkins, K. J. (1983). Journal of Craniofacial Genetics and Developmental Biology $3,11-17$.

Seller, M. J. \& Perkins, K. J. (1986). Teratology 33, 305-309.

Smithells, R. W., Nevin, N. C., Seller, M. J., Sheppard, S., Harris, R., Read, A. P., Fielding, D. W., Walker, S., Schorah, C. J. \& Wild, J. (1983). Lancet i, 1027-1031.

Smithells, R. W., Sheppard, S. \& Schorah, C. J. (1976). Archives of Diseases of Childhood 51, 944-950.

Smithells, R. W., Sheppard, S., Schorah, C. J., Seller, M. J., Nevin, N. C., Harris, R. \& Read, A. P. (1980). Lancet i, 339-340.

Stein, Z. \& Susser, M. (I976). In Birth Defects: Risks and Consequences, pp. 205-207|S. Kelly, E. B. Hook, D. T. Janerich and I. H. Porter, editors]. New York: Academic Press.

Thorogood, P., Smith, L., Nicol, A., McGinty, R. \& Garrod, D. (1982). Journal of Cell Science 57, $33 \mathrm{I}-350$.

Tolarova, M. (1982). Lancet ii, 217.

Warkany, J. \& Schraffenberger, E. (1943). Proceedings of the Society for Experimental Biology and Medicine 54, 92-94.

Warkany, J. \& Schraffenberger, E. (1944). Proceedings of the Society for Experimental Biology and Medicine 57, 49-52.

Wiley, M. J., Cauwenbergs, P. \& Taylor, I. M. (1983). Acta Anatomica 116, 180-192.

Wilson, J. G. \& Warkany, J. (1948). American fournal of Anatomy 83, 357-407.

Wilson, J. G. \& Warkany, J. (1950). Pediatrics 5, 708. 